\title{
Формирование двухфазной структуры в металлоорганическом перовските $\mathrm{CH}_{3} \mathrm{NH}_{3} \mathrm{PbI}_{3}$
}

\author{
(C) Д.В. Амасев ${ }^{1}$, В.Г. Михалевич ${ }^{1}$, А.Р. Тамеев ${ }^{2,3}$, Ш.Р. Саитов ${ }^{4}$, А.Г. Казанский ${ }^{4}$ ף \\ ${ }^{1}$ Институт общей физики им. А.М. Прохорова Российской академии наук, \\ 119991 Москва, Россия \\ ${ }^{2}$ Институт фризической химии и электрохимии им. А.Н. Фрумкина Российской академии наук, \\ 119071 Москва, Россия \\ ${ }^{3}$ Институт органического синтеза им. И.Я. Постовского Уральского отделения Российской академии наук, \\ 620137 Екатеринбург, Россия \\ ${ }^{4}$ Московский государственный университет им. М.В. Ломоносова, \\ 119991 Москва, Россия \\ ฯ E-mail: kazanski@phys.msu.ru
}

Поступила в Редакцию 28 января 2020 г.

В окончательной редакции 5 февраля 2020 г.

Принята к публикации 5 фревраля 2020 г.

Исследовано влияние отжига пленки металлоорганического перовскита $\mathrm{CH}_{3} \mathrm{NH}_{3} \mathrm{PbI}_{3}$ на его электрические, фотоэлектрические и оптические свойства. Показано, что отжиг при температуре $T_{a}>140^{\circ} \mathrm{C}$ приводит к формированию двухфазной структуры, состоящей из перовскита и иодида свинца, относительное содержание которых зависит от условий отжига, в частности от температуры. Формирование $\mathrm{PbI}_{2}$ в структуре перовскита приводит к уменьшению проводимости и фотопроводимости материала. Проведенные исследования указывают на возможность формирования планарных структур, состоящих из полупроводниковых материалов с различными величинами запрещенных зон: 1.6 э $\mathrm{B}\left(\mathrm{CH}_{3} \mathrm{NH}_{3} \mathrm{PbI}_{3}\right)$ и 2.4 э $\mathrm{B}\left(\mathrm{PbI}_{2}\right)$.

Ключевые слова: перовскиты, модификация отжигом, двухфазные пленки, фотопроводимость.

DOI: 10.21883/FTP.2020.06.49382.9358

\section{1. Введение}

В последние годы металлоорганические полупроводники со структурой перовскита привлекают к себе внимание в связи с большими возможностями создания на их основе эффективных тонкопленочных солнечных элементов. Одним из наиболее популярных материалов среди класса металлоорганических полупроводников является метиламмоний иодида свинца $\left(\mathrm{CH}_{3} \mathrm{NH}_{3} \mathrm{PbI}_{3}\right.$, MAPI). Структура этого металлоорганического полупроводника сформирована из атомов свинца, иода и органической молекулы метиламмония $\left(\mathrm{CH}_{3} \mathrm{NH}_{3}\right)$. Исследования показали, что в ряде случаев в сформированной пленке MAPI присутствует $\mathrm{PbI}_{2}$. Присутствие $\mathrm{PbI}_{2}$ в фотоактивном слое солнечного элемента (пленке перовскита) может быть вызвано как технологическими условиями получения материала [1], так и отжигом структуры при умеренной температуре $\left(\sim 150^{\circ} \mathrm{C}\right)[2,3]$.

Было показано, что наличие $\mathrm{PbI}_{2}$ в составе пленки перовскита влияет на параметры солнечных элементов, созданных на его основе. В частности, увеличение доли $\mathrm{PbI}_{2}$ в фотоактивном слое до 7.5 мол\% может привести к некоторому увеличению эффективности солнечного элемента. Увеличение эффективности структур авторы [4] объясняли тем, что наличие $\mathrm{PbI}_{2}$ в составе фотоактивных слоев способствует увеличению размеров микрокристаллов, формирующих их, и уменьшению темпа безызлучательной рекомбинации носителей заряда в пленках. При этом в указанных работах проводился в основном анализ влияния $\mathrm{PbI}_{2}$ на парамет- ры структуры, созданной на основе перовскита. В то же время представляет интерес исследование влияния присутствующего в пленке MAPI иодида свинца $\left(\mathrm{PbI}_{2}\right)$ на электрические и фотоэлектрические характеристики самой пленки.

Известно, что освещение пленки MAPI [5,6], нахождение во влажной атмосфере [7] или нагрев до умеренных температур [3] приводит к выделению $\mathrm{PbI}_{2}$ в структуре пленки MAPI. В представленной работе для формирования $\mathrm{PbI}_{2}$ в пленке использовался температурный отжиг. Поэтому было исследовано влияние температуры отжига пленки металлоорганического перовскита $\mathrm{CH}_{3} \mathrm{NH}_{3} \mathrm{PbI}_{3}$ на его электрические и фотоэлектрические свойства.

\section{2. Исследованные образцы и методика эксперимента}

В работе исследованы тонкие пленки перовскита $\mathrm{CH}_{3} \mathrm{NH}_{3} \mathrm{PbI}_{3}$, толщиной $350-400$ нм, осажденные на стеклянную подложку с использованием одноступенчатого метода. Исходный раствор, используемый для получения пленок $\mathrm{CH}_{3} \mathrm{NH}_{3} \mathrm{PbI}_{3}$, был изготовлен смешиванием компонентов метиламмония иодида $\mathrm{CH}_{3} \mathrm{NH}_{3} \mathrm{I}$ (MAI) и иодида свинца $\mathrm{PbI}_{2}$ в мольном соотношении $1: 1$ в безводном растворе диметилформамида (DMF) [8]. Данный одноступенчатый метод изготовления перовскита $\mathrm{CH}_{3} \mathrm{NH}_{3} \mathrm{PbI}_{3}$ при использованном нами соотношении $\mathrm{PbI}_{2}$ и MAI приводит к образованию материала с прово- 
димостью $n$-типа [9]. Исследования полученных пленок $\mathrm{CH}_{3} \mathrm{NH}_{3} \mathrm{PbI}_{3}$ методом сканирующей электронной микроскопии показали, что пленки имеют микрокристаллическую структуру со средним размером микрокристаллов $\sim 350$ нм.

Для проведения электрических и фотоэлектрических измерений в планарной конфигурации контактов на поверхность пленки методом термического напыления были нанесены контакты из золота. Расстояние между контактами составляло $0.2 \mathrm{Mм}$.

В работе исследовалось влияние температуры отжига $\left(T_{a}\right)$ на темновую проводимость $\sigma_{d}$ и фотопроводимость $\Delta \sigma_{\mathrm{ph}}=\sigma_{\mathrm{ph}}-\sigma_{d}$ (где $\sigma_{\mathrm{ph}}-$ проводимость при освещении) пленки металлоорганического перовскита MAPI. Измерения спектральных зависимостей фотопроводимости проводились при комнатной температуре после отжига пленки в вакууме при заданной температуре отжига $T_{a}$ в течение 10 мин. Температура при последовательных отжигах повышалась от 60 до $160^{\circ} \mathrm{C}$. Все измерения выполнялись в вакууме при остаточном давлении $\sim 10^{-3}$ Па и при приложенном к образцу напряжении в области линейности вольт-амперной характеристики.

\section{3. Результаты экспериментов и их обсуждение}

На рис. 1 показаны спектральные зависимости фотопроводимости пленки перовскита, нормированные на число падающих квантов $(N)$ после последовательных отжигов пленки при различных температурах. Как видно из рисунка, при температурах отжига $T_{a} \leq 120^{\circ} \mathrm{C}$ спектральные зависимости фотопроводимости близки по характеру. В области энергий квантов $<1.6$ эВ наблюдается резкое экспоненциальное уменьшение фотопроводимости, что свидетельствует о наличии в исследованных пленках $\mathrm{CH}_{3} \mathrm{NH}_{3} \mathrm{PbI}_{3}$ запрещенной зоны шириной $\sim 1.6$ эВ. При энергиях квантов $h v>1.6$ эВ фотопроводимость слабо зависит от энергии падающих квантов. Из рисунка видно, что при $T_{a} \leq 120^{\circ} \mathrm{C}$ с ростом $T_{a}$ в области $h v>1.6$ эВ наблюдается лишь небольшое уменьшение фотопроводимости и формирование некоторой особенности при $h v>2.25$ эВ.

Наиболее резкое изменение характера спектральной зависимости и величины фотопроводимости происходит после отжига пленки при $T_{a}=140^{\circ} \mathrm{C}$. Наблюдается существенное уменьшение величины фотопроводимости во всем исследованном спектральном диапазоне. При этом в области энергий квантов $h v>2.25$ эВ формируется „второй край“ фотопроводимости. Примечательно, что после отжига при $T_{a}=160^{\circ} \mathrm{C}$ происходит изменение цвета пленки, расположенной между контактами, с темно-коричневого на желтый. Согласно [3], высокотемпературный отжиг приводит к термическому разложению MAPI на MAI и $\mathrm{PbI}_{2}$. Таким образом, наблюдаемое изменение спектральных зависимостей фотопроводимости пленки перовскита после ее отжига при $T_{a}=140^{\circ} \mathrm{C}$

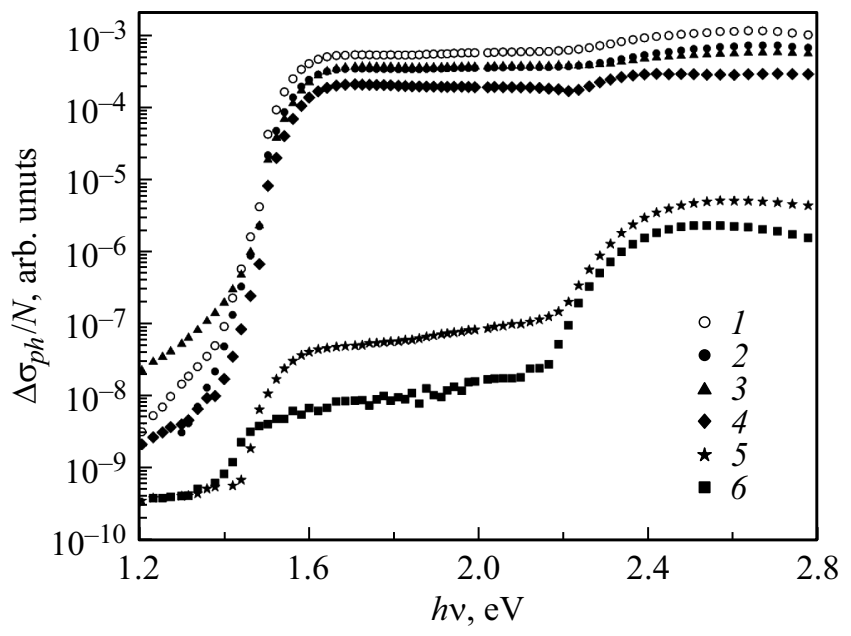

Рис. 1. Спектральные зависимости фотопроводимости при комнатной температуре, нормированные на число падающих квантов, для пленки перовскита, отожженной при температу$\operatorname{pax} T_{a}=60(1), 80(2), 100(3), 120(4), 140(5), 160^{\circ} \mathrm{C}(6)$.

связано с изменением состава пленки и формированием в ее структуре иодида свинца $\mathrm{PbI}_{2}$, ширина запрещенной зоны которого составляет 2.4 эВ [1].

Характер спектральных зависимостей фотопроводимости указывает на то, что в формировании фотопроводимости исследованной пленки после ее отжига при 140 и даже при $160^{\circ} \mathrm{C}$ принимают участие как содержащийся в пленке перовскит $\mathrm{CH}_{3} \mathrm{NH}_{3} \mathrm{PbI}_{3}$ с шириной запрещенной зоны 1.6 эВ, так и иодид свинца $\mathrm{PbI}_{2}$ с шириной запрещенной зоны 2.4 эВ. Как видно из рисунка, после отжига пленки при $T_{a}=140^{\circ} \mathrm{C}$ уменьшение фотопроводимости происходит в большей степени при энергиях квантов $<2.25$ эВ. Однако наличие фотопроводимости в области $h v=1.6-2.25$ эВ указывает на вклад $\mathrm{CH}_{3} \mathrm{NH}_{3} \mathrm{PbI}_{3}$ в генерацию неравновесных носителей заряда в сформированной двухфазной пленке. В то же время большее на 1.5-2 порядка величины значение фотопроводимости при $h v>2.4$ эВ по сравнению с фотопроводимостью при $h v<2.25$ эВ указывает на определяющую роль иодида свинца в переносе и генерации при $h v>2.4$ эВ неравновесных носителей заряда в пленке, отожженной при $T_{a}=140$ и $160^{\circ} \mathrm{C}$. Таким образом, можно предположить, что в двухфазном материале, сформированном после отжига исходной пленки перовскита при $T_{a}=160^{\circ} \mathrm{C}$, генерация неравновесных носителей заряда происходит как в перовските, так и в иодиде свинца. Перенос же носителей заряда, по-видимому, осуществляется по иодиду свинца $\left(\mathrm{PbI}_{2}\right)$. При этом вклад $\mathrm{CH}_{3} \mathrm{NH}_{3} \mathrm{PbI}_{3}$ в фотопроводимость может быть связан с близостью энергетических положений краев зон проводимости $\mathrm{CH}_{3} \mathrm{NH}_{3} \mathrm{PbI}_{3}$ и $\mathrm{PbI}_{2}$ [1]. Уменьшение фотопроводимости полученного двухфазного материала во всем исследованном спектральном диапазоне может быть связано как с увеличением концентрации центров рекомбинации и соответственно уменьшением времени жизни, так и с уменьшением подвижности неравновесных носителей заряда. 


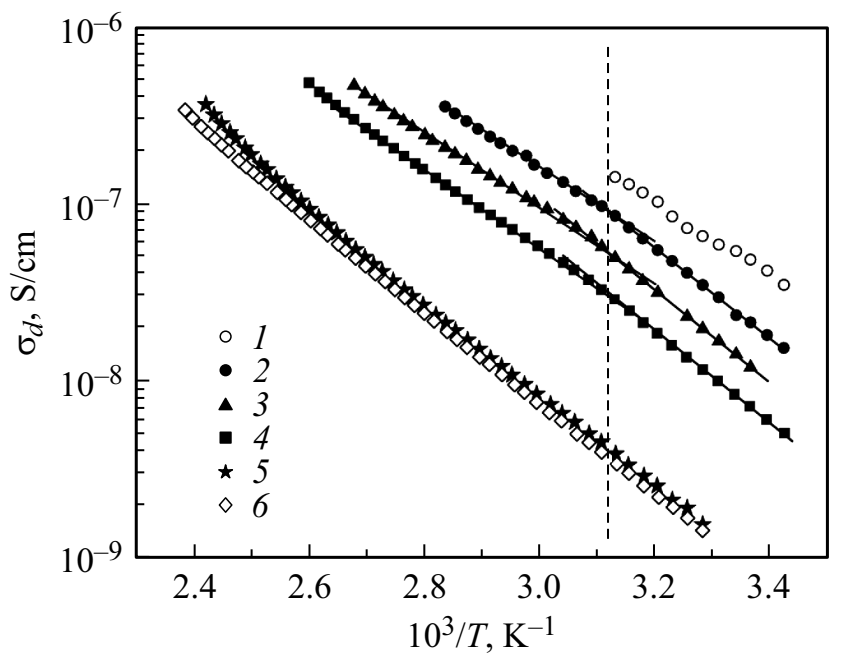

Рис. 2. Температурные зависимости проводимости для пленки перовскита, отожженной при температурах $T_{a}=60$ (1), 80 (2), $100(3), 120(4), 140(5), 160^{\circ} \mathrm{C}(6)$.

На существенное уменьшение подвижности в исследованных пленках перовскита, отожженных при высоких температурах, указывает изменение проводимости пленок при их отжиге. На рис. 2 показано влияние последовательного отжига при различных температурах на температурную зависимость проводимости $\sigma_{d}(T)$ исследованной пленки перовскита. Измерения проводились при понижении температуры после отжига пленки в вакууме при $T_{a}$ в течение 10 мин.

Как видно из рис. 2 , вид температурных зависимостей близок к активационному. При этом по характеру изменения полученные зависимости можно разделить на два класса: зависимости, полученные для пленки, отожженной при температурах $T_{a} \leq 120^{\circ} \mathrm{C}$, и для пленки, отожженной при бо́льших температурах $\left(140\right.$ и $\left.160^{\circ} \mathrm{C}\right)$. В первом случае на температурных кривых проводимости можно выделить область вблизи температуры $T=330 \mathrm{~K}$ (показана вертикальной штриховой линией), при которой наблюдается некоторое изменение энергии активации проводимости $\left(E_{a}\right)$ от $\sim(0.51-0.52)$ эВ при меньших температурах до $\sim(0.41-0.44)$ эВ при бо́льших температурах. Это может быть связано с фазовым переходом в структуре перовскита при указанной температуре [10]. Из рисунка также видно, что увеличение температуры отжига до $T_{a}=120^{\circ} \mathrm{C}$ приводит к некоторому уменьшению проводимости. В то же время после отжига при $T_{a}=140^{\circ} \mathrm{C}$ наблюдается резкое уменьшение проводимости. При этом температурные зависимости проводимости, полученные после отжига при $T_{a}=140$ и $160^{\circ} \mathrm{C}$, близки между собой. Величина энергии активации из этих зависимостей близка к значению энергии активации, полученной для „низкотемпературной“ области в случае пленки, отожженной при $T_{a} \leq 120^{\circ} \mathrm{C}$, и составляет $0.54-0.55$ эВ. Отметим также, что на температурных зависимостях проводимости, полученных после отжига при 140 и $160^{\circ} \mathrm{C}$, не наблюдается двух явно выраженных участков с разными энергиями активации.

Наблюдаемое некоторое уменьшение проводимости после отжига пленки при $T_{a} \leq 120^{\circ} \mathrm{C}$ можно объяснить формированием широкозонного $\mathrm{PbI}_{2}$ на границах раздела микрокристаллов перовскита [3] и соответственно уменьшением подвижности носителей заряда. В то же время, как и в случае представленных выше спектральных зависимостей фотопроводимости, резкое уменьшение величины проводимости после отжига пленки при $T_{a}=140^{\circ} \mathrm{C}$ можно объяснить существенным увеличением доли $\mathrm{PbI}_{2}$ в составе исследованного материала в результате отжига пленки. Проводимость в исследованном материале определяется концентрацией и величиной подвижности носителей заряда. Как видно из рис. 2, отжиг исследованной пленки перовскита приводил к уменьшению величины проводимости более чем на порядок. При этом энергия активации температурной зависимости существенно не изменялась. Известно, что энергия активации температурных зависимостей проводимости неупорядоченных полупроводников в основном определяется положением уровня Ферми относительно уровня протекания носителей заряда. В свою очередь положение уровня Ферми определяет концентрацию „свободных“ носителей заряда. Полученные результаты указывают на то, что в результате отжига не происходит существенного изменения положения уровня Ферми относительно уровня протекания в сформированной двухфазной пленке. В этом случае вызванное отжигом уменьшение проводимости может быть связано с уменьшением подвижности носителей заряда в сформированном в результате отжига двухфазном материале, основную долю в котором составляет иодид свинца $\mathrm{PbI}_{2}$.

Заметим, что представленная выше интерпретация полученных результатов основывалась на предположении об однородной структуре пленки по ее толщине и поверхности после ее отжига. В то же время, согласно [3], выделение с поверхности пленки при отжиге перовскита молекул метиламмония может привести к неоднородному по толщине двухфазному составу пленки. Возможность этого следует из рис. 3 , на котором показан исследованный образец после отжига при $T_{a}=160^{\circ} \mathrm{C}$.

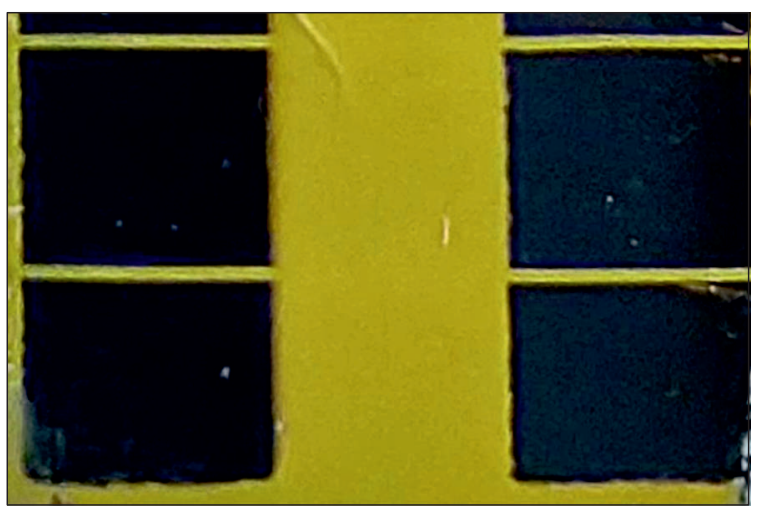

Рис. 3. Фотография образца после его отжига при $T_{a}=160^{\circ} \mathrm{C}$. 
Как видно из фотографии (рис. 3), в областях, которые были покрыты золотыми контактами, в результате отжига цвет пленки не изменился. Это может свидетельствовать о том, что в этих местах в результате отжига не произошло существенного выделения иодида свинца из пленки и соответственно изменения состава пленки. Наличие перовскита под контактами и возможность существования „обогащенного“ перовскитом слоя вблизи подложки может привести к наблюдаемому вкладу перовскита в фотопроводимость пленок, отожженных при высоких температурах. Возможность реализации данного эффекта требует дальнейших исследований.

\section{4. Заключение}

В работе исследовано влияние отжига пленки металлоорганического перовскита $\mathrm{CH}_{3} \mathrm{NH}_{3} \mathrm{PbI}_{3}$ на его электрические, фотоэлектрические и оптические свойства. Показано, что отжиг при $T_{a}>140^{\circ} \mathrm{C}$ приводит к формированию двухфазной структуры, состоящей из перовскита и иодида свинца, относительное содержание которых зависит от условий отжига, в частности от его температуры. Формирование $\mathrm{PbI}_{2}$ в структуре перовскита приводило к уменьшению проводимости и фотопроводимости материала. Это указывает на то, что отмеченное в работах $[1,3]$ улучшение параметров солнечных элементов на основе $\mathrm{CH}_{3} \mathrm{NH}_{3} \mathrm{PbI}_{3}$ при введении в него $\mathrm{PbI}_{2}$, повидимому, не связано с улучшением фотоэлектрических параметров самого фотоактивного слоя. Проведенные исследования указывают на возможность формирования планарных тонкопленочных структур, состоящих из полупроводниковых материалов с различными величинами запрещенных зон: 1.6 эВ $\left(\mathrm{CH}_{3} \mathrm{NH}_{3} \mathrm{PbI}_{3}\right)$ и 2.4 эB $\left(\mathrm{PbI}_{2}\right)$.

\section{Финансирование работы}

Работа проведена при финансовой поддержке РФФИ (проект 18-32-00417 - эксперимент), РНФ (проект 18-13-00409 - анализ результатов).

\section{Конфликт интересов}

Авторы заявляют, что у них нет конфликта интересов.

\section{Список литературы}

[1] D. Cao, C. Stoumpos, C. Malliakas, M. Katz, O. Farha, J. Hupp, M. Kanatzidis. Appl. Mater., 2, 091101 (2014).

[2] Q. Chen, H. Zhou, T. Song, S. Luo, Z. Hong, H. Duan, L. Dou, Y. Liu, Y. Yang. Nano Lett., 14, 4158 (2014).

[3] T. Du, C. Burgess, J. Kim, J. Zhang, J. Durrant, M. McLachlan. Sustainable Energy \& Fuels, 1, 119 (2017).

[4] Y. Kim, N. Jeon, J. Noh, W. Yang, J. Seo, J. Yun, A. HoBaillie, S. Huang, M. Green, J. Seidel, T. Ahn, S. Seok. Adv. Energy Mater., 6, 1502104 (2016).
[5] J. Barb'e, M. Newman, S. Lilliu, V. Kumar, H. Ka, H. Lee, C. Charbonneau, C. Rodenburg, D. Lidzey, W. Tsoi. J. Mater. Chem. A, 6, 23010 (2018).

[6] C. Bi, Y. Shao, Y. Yuan, Z. Xiao, C. Wang, Y. Gao, J. Huang. J. Mater. Chem. A, 2, 18508 (2014).

[7] R. Misra, S. Aharon, B. Li, D. Mogilyansky, I. Visoly-Fisher, L. Etgar, E. Katz, J. Phys. Chem. Lett., 6, 326 (2015).

[8] D. Saranin, V. Mazov, L. Luchnikov, D. Lypenko, P. Gostishev, D. Muratov, D. Podgorny, D. Migunov, S. Didenko, M. Orlova, D. Kuznetsov, A. Tameev, A. Di Carlo. J. Mater. Chem. C, 6, 6179 (2018).

[9] Q. Wang, Y. Shao, H. Xie, L. Lyu, X. Liu, Y. Gao, J. Huang. Appl. Phys. Lett., 105, 163508 (2014).

[10] T. Baikie, Y. Fang, J. Kadro, M. Schreyer, F. Wei, S. Mhaisalkar, M. Graetzel, T. White. J. Phys. Chem. A, 1, 5628 (2013).

Редактор Л.В. Шаронова

\section{Formation of two-phase structure in $\mathrm{CH}_{3} \mathrm{NH}_{3} \mathrm{Pbl}_{3}$ organometallic perovskite}

\author{
D.V. Amasev ${ }^{1}$, V.G. Mikhalevich ${ }^{1}$, A.R. Tameev ${ }^{2,3}$, \\ S.R. Saitov ${ }^{4}$, A.G. Kazanskii ${ }^{4}$ \\ ${ }^{1}$ Prokhorov General Physics Institute, \\ Russian Academy of Sciences, \\ 119991 Moscow, Russia \\ ${ }^{2}$ Frumkin Institute of Physical Chemistry and \\ Electrochemistry, \\ Russian Academy of Sciences, \\ 119071 Moscow, Russia \\ ${ }^{3}$ Postovsky Institute of Organic Synthesis \\ of the Ural Branch, Russian Academy of Sciences, \\ 620137 Ekaterinburg, Russia \\ ${ }^{4}$ Lomonosov Moscow State University, \\ 119991 Moscow, Russia
}

Abstract The effect of annealing of an organometallic perovskite $\mathrm{CH}_{3} \mathrm{NH}_{3} \mathrm{PbI}_{3}$ film on its electrical, photoelectric, and optical properties is studied. It was shown that annealing at the temperature $T_{a}>140^{\circ} \mathrm{C}$ leads to formation of a two-phase structure consisting of perovskite and lead iodide, the relative content of which depends on the annealing conditions, in particular on its temperature. $\mathrm{PbI}_{2}$ formation in the perovskite structure leads to a decrease in the conductivity and photoconductivity of the material. Our studies indicate the possibility of forming planar structures consisting of semiconductor materials with various values of the band gap: $1.6 \mathrm{eV}\left(\mathrm{CH}_{3} \mathrm{NH}_{3} \mathrm{PbI}_{3}\right)$ and $2.4 \mathrm{eV}\left(\mathrm{PbI}_{2}\right)$. 